\title{
A prospective randomized comparison of the Medtronic Advantage Supra and St Jude Medical Regent mechanical heart valves in the aortic position: Is there an additional benefit of supra-annular valve positioning?
}

Ralf Guenzinger, MD, Walter Benno Eichinger, MD, Ina Hettich, MD, Sabine Bleiziffer, MD, Daniel Ruzicka, MD, Robert Bauernschmitt, MD, and Ruediger Lange, MD

Earn CME credits at http:// cme.ctsnetjournals.org
From the Department of Cardiovascular Surgery, German Heart Center Munich, Technical University of Munich, Munich, Germany.

The study protocol was discussed with the companies Medtronic Inc (Minneapolis, Minn) and St Jude Medical Inc (St Paul, Minn). The follow-up examinations and echocardiography were financially supported in equal parts by Medtronic Inc and St Jude Medical Inc.

Received for publication Sept 11, 2007; revisions received Dec 6, 2007; accepted for publication Dec 18, 2007.

Address for reprints: Ralf Guenzinger, MD, German Heart Center Munich, Technical University of Munich, Lazarettstrasse 36, 80636 Munich, Germany (E-mail: guenzinger@dhm.mhn.de).

J Thorac Cardiovasc Surg 2008;136:462-71 $0022-5223 / \$ 34.00$

Copyright (C) 2008 by The American Association for Thoracic Surgery

doi:10.1016/j.jtcvs.2007.12.018
Objective: The aim of this prospective randomized trial was to evaluate the impact of complete supraannular positioning of mechanical aortic bileaflet valves.

Methods: Between April of 2004 and November of 2006, 80 patients underwent aortic valve replacement with the complete supraannular Medtronic Advantage Supra ( $\mathrm{n}=$ 40) (Medtronic Inc, Minneapolis, Minn) or the intra-supraannular St Jude Medical Regent $(n=40)$ prosthesis (St Jude Medical Inc, St Paul, Minn). Before randomization and valve sizing for both valve types, the aortic tissue annulus diameter was determined by Hegar dilator. Transthoracic echocardiography data were obtained early postoperatively and at 6 months, including stress echocardiography.

Results: By grouping the data on the basis of a patient's tissue annulus diameter, no significant difference of either valve was detected with regard to mean pressure gradient and effective orifice area index at rest. Effective orifice area index ranged from $0.95 \pm 0.32 \mathrm{~cm}^{2} / \mathrm{m}^{2}$ to $1.27 \pm 0.33 \mathrm{~cm}^{2} / \mathrm{m}^{2}$ in the Advantage Supra group and from $0.98 \pm 0.36 \mathrm{~cm}^{2} / \mathrm{m}^{2}$ to $1.26 \pm 0.37 \mathrm{~cm}^{2} / \mathrm{m}^{2}$ in the Regent group. During exercise, mean pressure gradients increased from $11.9 \pm 4.9 \mathrm{~mm} \mathrm{Hg}$ to $19.1 \pm 7.2 \mathrm{~mm} \mathrm{Hg}$ in the Advantage Supra group and from $9.6 \pm 4.0$ to $16.4 \mathrm{~mm} \mathrm{Hg} \pm 7.3 \mathrm{~mm} \mathrm{Hg}$ in the Regent group. A marked left ventricular mass regression across all annulus sizes was noted in both groups $(P<.001)$. Sizing for both valve types showed that in $26.3 \%$, the completely supraannular valve design allows the implantation of a 1 size larger valve in label than the corresponding intra-supraannular valve.

Conclusion: By grouping the data on the basis of a patient's tissue annulus diameter, no significant superiority of either prosthesis was detected with regard to left ventricular mass regression, effective orifice area index, and mean pressure gradient during rest and exercise. We conclude that there is no additional benefit of supraannular valve positioning.

A ortic valve replacement (AVR) is the treatment of choice for advanced calcified aortic valve stenosis and has developed into a routine method with a low complication rate. ${ }^{1}$ The surgeon aims for the best hemodynamic result that is realized by maximizing the overall area available for blood flow.

Today, several bileaflet mechanical heart valves, which are similar in design, are available. All of them are considered to offer good hemodynamic function and almost unlimited durability and thus serve as the current standard for mechanical heart valve replacement. ${ }^{2,3}$ Initially, valve prostheses were designed for intra-annular placement. However, this may reduce the available area for transvalvular blood flow and may leave the patient with a residual pressure gradient, especially in the small-sized annulus. 


$$
\begin{aligned}
& \text { Abbreviations and Acronyms } \\
& \text { AVR }=\text { aortic valve replacement } \\
& \text { EOA }=\text { effective orifice area } \\
& \text { EOAI }=\text { effective orifice area index } \\
& \text { EOF }=\text { effective orifice fraction } \\
& \text { LV }=\text { left ventricular } \\
& \text { LVM }=\text { left ventricular mass } \\
& \text { LVOT }=\text { left ventricular outflow tract } \\
& \text { MPG }=\text { mean pressure gradient } \\
& \text { PPM }=\text { patient-prosthesis mismatch }
\end{aligned}
$$

Manufacturers have therefore designed intra-supraannular valves with a reduced sewing ring, such as the St Jude Medical Regent valve (St Jude Medical Inc, St Paul, Minn) in which only the pivot guards remain intra-annular. This has already shown excellent hemodynamic results. ${ }^{4,5}$ To further improve the hemodynamic performance, manufacturers constructed complete supraannular valves in which the complete housing is placed above the tissue annulus, such as the Medtronic Advantage Supra valve (Medtronic Inc, Minneapolis, Minn). With this complete supraannular positioning, no parts of the valve housing protrude into the outflow area and the valve's orifice can theoretically be the same size as the patient's tissue annulus (Figure 1, $A$ and $B$ ).

However, up to the present there have been no comparative studies of both valve types to show whether the complete supraannular design offers a further advantage. Therefore, the aim of this prospective randomized study was to evaluate the early hemodynamic and clinical performance of these 2 mechanical aortic valve prostheses during rest and exercise, to analyze the impact of complete supraannular valve positioning, and to evaluate prosthesis-specific differences in valve sizing and valve size labeling.

\section{Materials and Methods Patients' Enrollment}

Between April of 2004 and November of 2006, 80 patients who were diagnosed with aortic stenosis or mixed lesion that required AVR entered the study. Patients with pure aortic regurgitation; valve size 27 or more; emergency surgery; endocarditis; double valve replacement; age less than 18 years; preexisting valve prosthesis in mitral, pulmonic, or tricuspid position; nonstudy valve surgeon; unfavorable geographic location; or refusal of study participation were excluded from enrolment. During surgery, patients were randomized to receive either the Medtronic Advantage Supra valve or the St Jude Medical Regent valve. The study was approved by the institutional ethics committee. Informed consent was obtained from each participant. Early follow-up was within 10 days postoperatively by transthoracic echocardiography at rest. Six months postoperatively, patients were followed up including transthoracic echocardiography at rest and at stress using bicycle exercise. Valve-related complications were documented at the time of appearance. Follow-up was $100 \%$ complete.

\section{Echocardiography}

Transthoracic Doppler echocardiography was performed in accordance with the data requirements of the Food and Drug Administration Replacement Heart Valve Guidance, Version 4.1. ${ }^{6}$

Echocardiographic measurements performed at rest included the transvalvular mean and maximal flow velocity, mean and maximal pressure gradient, and velocity time integral using continuous-wave Doppler. Pulsed-wave Doppler was used for the same measurements in the left ventricular outflow tract (LVOT). LVOT diameter was assessed from a parasternal long-axis view using an expanded (zoom) view. The same measurements were performed during exercise, except for LVOT diameter, which was assumed to remain constant.

The mean systolic pressure gradient was calculated as the difference of mean aortic and mean LVOT gradient. During rest and exercise, the flow velocity recording was first performed in the transvalvular jet and then in the LVOT. To ensure detection of the highest velocities, a minimum of 2 transducer positions was attempted in all patients. From these measurements, we calculated the left ventricular (LV) stroke volume (LVOT velocity time integral [cm] * LVOT area $\left.\left[\mathrm{cm}^{2}\right]\right)$. The effective orifice area (EOA) was calculated using the standard continuity equation. The echocardiographically obtained hemodynamic results were referred to aortic tissue annulus diameter (Hegar dilator measurement) instead of labeled valve size by means of effective orifice fraction (EOF), which reflects the ratio of EOA and aortic tissue annulus area. This procedure makes an objective comparison of different valve types easier because of well known differences in valve size labeling. ${ }^{7}$

LV end-systolic and end-diastolic dimensions and thickness of the LV posterior wall and interventricular septum were assessed in the parasternal view by multiple M-mode measurements. ${ }^{8}$ Left ventricular mass (LVM) was calculated using the appropriate formula suggested by the American Society of Echocardiography and indexed by body surface area. ${ }^{9}$

\section{Stress Echocardiography Protocol}

Stress echocardiography was performed by bicycle exercise testing, as described by Pibarot and colleagues ${ }^{10}$ and Eriksson and colleagues. ${ }^{11}$ During bicycle exercise, patients sat on a seat reclined in a 50-degree position. The starting workload was $25 \mathrm{~W}$ and was then increased by $25 \mathrm{~W}$ every 2 minutes. The patients were encouraged to exercise until exhaustion. The test was stopped if there was no increase or an abnormal increase in blood pressure (diastolic blood pressure $>110 \mathrm{~mm} \mathrm{Hg}$ ), electrocardiographic evidence of ischemia (horizontal or downsloping S-T depression, S-T lifting), significant arrhythmia (new atrial fibrillation, ventricular arrhythmia), chest pain, vertigo, tachycardia ( $>200$ beats/min minus age), or dyspnea. To facilitate Doppler measurements during exercise, the chest site, where optimum Doppler waveforms were recorded, was marked before starting exercise. In case of an unsatisfactory Doppler signal, the whole bicycle unit (ERGOLINE ergometrics er900EL Version 05/02, Bitz, Germany) was tilted slightly to the left side until optimal measurements were obtained. Velocity recordings were performed at the end of each 2-minute workload level and were stored to the system. Blood pressure was measured noninvasively every 2 minutes using a sphygmomanometer cuff fixed on the right arm. A 12-lead electrocardiogram was continuously recorded. ${ }^{7}$ Maximal and mean velocities, maximal pressure gradient, 

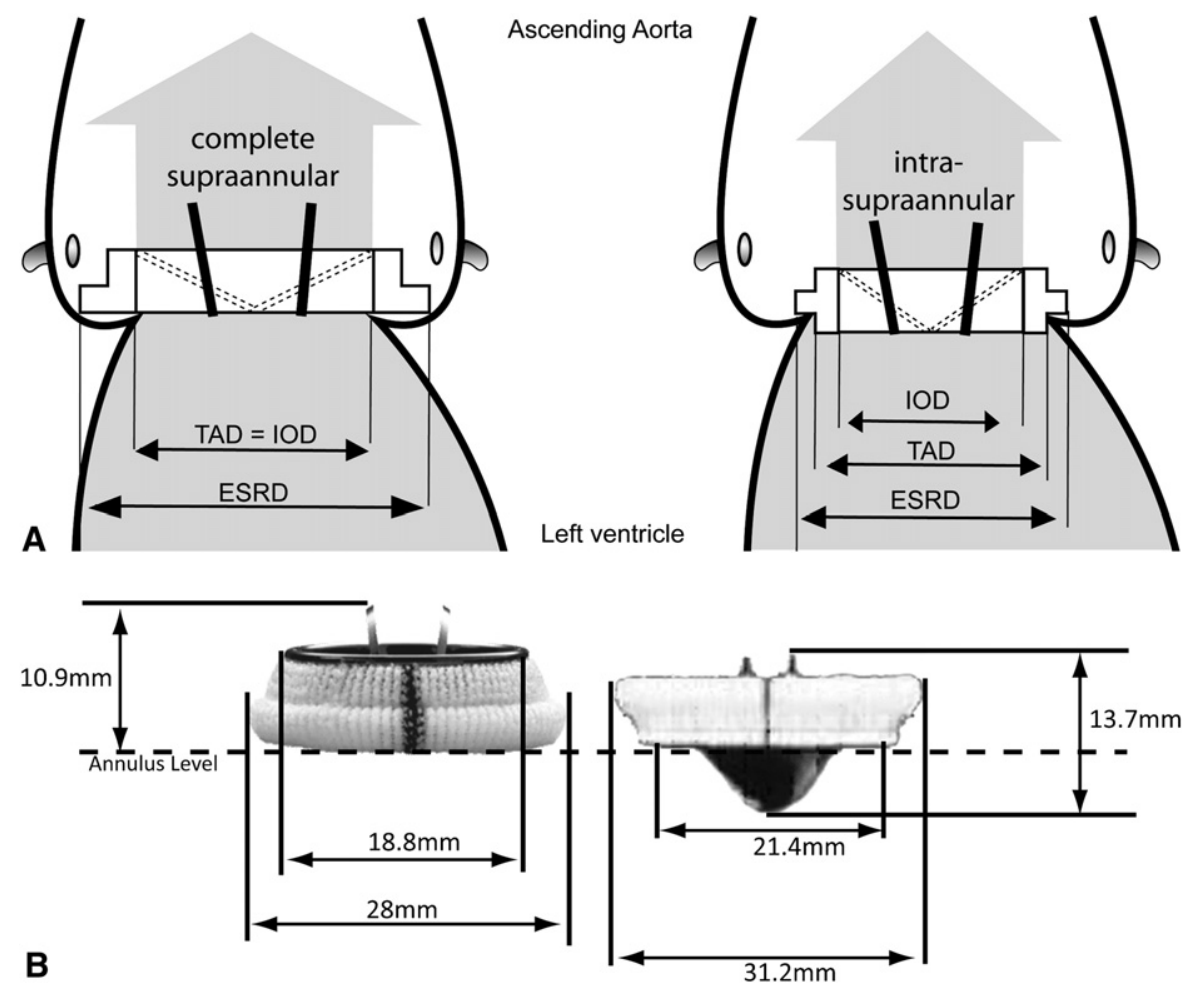

Figure 1. A, Implant positions of the complete supraannular Medtronic Advantage Supra (left) (Medtronic Inc, Minneapolis, Minn) and the intra-supraannular St Jude Medical Regent valve (right) (St Jude Medical Inc, St Paul, Minn). B, Profile and dimensions (in millimeters) of a labeled valve size 23. Left side: complete supraannular Medtronic Advantage Supra ${ }^{\circledR}$. Right side: intrasupraannular St. Jude Med. IOD, Internal orifice diameter; $T A D$, tissue annulus diameter; ESRD, external sewing ring diameter or aortic annulus diameter. mean pressure gradient (MPG), and velocity time integral were calculated by loading the stored velocity recordings.

\section{Patient-Prosthesis Mismatch}

The effective orifice area index (EOAI) is the decisive parameter to describe the incidence of patient-prosthesis mismatch (PPM). We used the Doppler-derived EOA 6 months postoperatively to calculate the EOAI. We rated the extent of PPM as not present for EOAI greater than $0.85 \mathrm{~cm}^{2} / \mathrm{m}^{2}$, moderate for EOAI between 0.65 and $0.85 \mathrm{~cm}^{2} / \mathrm{m}^{2}$, and severe for EOAI equal to or less than 0.65 $\mathrm{cm}^{2} / \mathrm{m}^{2}$, as described by Pibarot and colleagues. ${ }^{12}$ This graduation corresponds to the general concept that moderate aortic stenosis of a native valve is present with EOAI less than $0.90 \mathrm{~cm}^{2} / \mathrm{m}^{2} .13$

\section{Valve Specifications}

The Medtronic Advantage Supra valve was first implanted in July of 2003; has regulatory approvals for Europe, Canada, Australia, and Japan; and is a development of the existing Medtronic Advantage valve without changing the pivot region and pivot guards. By increasing the distance between the leaflets, the Advantage valve's wider central opening area increases central flow, reduces turbulence, and shows good hemodynamics during rest and exercise. ${ }^{14-16}$ By raising the complete housing above the tissue annulus, the whole valve can be placed in a completely supraannular position so that the tissue annulus contains no valve parts (Figure 1, $A$ and $B$ ).

The St Jude Medical Regent valve is a development of the existing St Jude Medical Standard and St Jude Medical Hemodynamic Plus valves without changing the existing design of the pivot mechanism or blood-contact surface areas. The St Jude Regent bileaflet valve is designed with a reduced sewing ring to achieve a larger
EOA and improved hemodynamics. ${ }^{4,5}$ The cuff of the valve is raised above the tissue annulus while the struts remain intraannular. Therefore, the St Jude Medical Regent prosthesis will be implanted in an intra-supraannular way (Figure 1, $A$ and $B$ ).

\section{Valve Sizing}

After removal of the native aortic valve and decalcification of the annulus, every surgeon determined the aortic annulus diameter by insertion of a neutral sizer (Hegar dilator). Afterwards, sizing for both valve types was undertaken in each patient using the appropriate valve sizer provided by each manufacturer (Medtronic Advantage Supra or St Jude Medical Regent). Thereby the surgeon committed to the specific valve size before randomization.

\section{Randomization}

Randomization was performed in the operating room using the sealed envelope technique after patient eligibility was confirmed and valve sizing for both valve types was completed. Patients were randomized to receive either the Medtronic Advantage Supra or the St Jude Medical Regent valve. This protocol was designed to prevent surgeon-specific selection bias.

\section{Implantation Technique}

AVR was undertaken through a complete or minimally invasive partial sternotomy using standard cardiopulmonary bypass under mild hypothermia $\left(32^{\circ} \mathrm{C}\right)$ with cold crystalloid cardioplegia and topical surface cooling. There was no difference in the operative technique between both valve types. The mechanical prostheses were implanted with pledged-supported, interrupted, non-everting mattress sutures. 


\section{Statistical Analysis}

Data are presented as mean \pm standard deviation. Comparisons between both groups were made by the $t$ test for independent samples in case of normal data distribution and the Mann-Whitney $U$ test in case of non-normal data distribution. Comparisons within 1 group were performed by using the Wilcoxon matched-pairs test. All statistical analyses were performed with the Statistical Package for the Social Sciences version 14.0 (SPSS Inc, Chicago, Ill).

\section{Results}

\section{Patients}

Between April of 2004 and November of 2006, 253 patients underwent AVR with a mechanical prosthesis at the German Heart Center Munich, Germany. A total of 173 of those patients were not able to enter the study because of exclusion criteria, that is, pure aortic regurgitation $(\mathrm{n}=17)$; valve size $\geq$ $27(n=12)$; emergency surgery $(n=7)$; endocarditis $(n=20)$; double valve replacement $(n=35)$; age $<18$ years $(n=17)$; preexisting valve prosthesis in mitral, pulmonic, or tricuspid position $(n=18)$; nonstudy valve surgeon $(n=25)$; unfavorable geographic location $(\mathrm{n}=8)$; or refusal of study participation $(n=14)$. Finally, 80 patients $(74.4 \%$ were male) entered the study and were randomly assigned to receive either the Medtronic Advantage Supra valve $(\mathrm{n}=40)$ or the St Jude Medical Regent valve ( $\mathrm{n}=40)$. Follow-up is $100 \%$ complete. Aortic valve pathology was isolated stenosis $(n=46)$ or mixed lesion $(\mathrm{n}=34)$. Mean age at implantation was 55.6 \pm 9.3 years, and mean ejection fraction was $56.5 \% \pm$ $15.8 \%$. Both study groups did not differ significantly with regard to age, gender, distribution of preoperative New York Heart Association class, ejection fraction, and LVM index. Preoperative data of each group are summarized in Table 1.

\section{Operative Data and Adverse Events}

The overall 30 -day mortality was $1.25 \%$. One patient died of mesenteric ischemia in the Medtronic Advantage Supra group. In 1 case, a Medtronic Advantage Supra valve was replaced intraoperatively because of suspected obstruction of the coronary ostia. In this case, Hegar measurement revealed an annulus diameter of $23 \mathrm{~mm}$ and valve sizing revealed a labeled valve size 23 for both prostheses. After removal of the Medtronic Advantage Supra valve size 23, a St Jude Medical Regent valve size 21 was implanted without any further problems. Minimally invasive partial sternotomy was performed in $68.9 \%$ of isolated AVR. The mean aortic crossclamp time was $72.0 \pm 17.2$ minutes for isolated procedures and $84.8 \pm 21.7$ minutes for combined procedures.

On the basis of equal tissue annulus diameters, labeled valve sizes tended to be bigger in the Medtronic Advantage Supra group (not significant) (Table 1). Valve sizing for both valve types before randomization showed that in 26.3\% the Medtronic Advantage Supra valve can be implanted 1 size larger in labeled size than the St Jude Medical Regent valve. Both study groups did not differ significantly with regard to mortality, valve size distribution, aortic annulus diameter, and aortic crossclamp time. Operative data of each group are summarized in Table 1 .

There was no difference in the frequency of clinical events. There was 1 transient ischemic attack in the Medtronic Advantage Supra group and 1 case of antithromboembolic hemorrhage (gastrointestinal bleeding) in the St Jude Medical Regent group. In both groups, there were no other prosthesisrelated adverse events, such as prosthetic valve endocarditis or reoperations in the first 6 months postoperatively.

\section{Hemodynamic Data During Rest and Exercise}

MPG, EOAI, stroke volume, and EOF of the Medtronic Advantage Supra valve and the St Jude Medical Regent valve at discharge, grouped by aortic tissue annulus diameter, are depicted in Table 2.

The mean systolic pressure gradients during treadmill exercise are depicted in Figure 2, $A$, grouped by aortic tissue annulus diameter and exercise level. In addition, the corresponding stroke volume of each subgroup is shown to refer potential differences in MPG to differences in volume load (Figure 2,B). Exercise data are complete for 31 patients in the Advantage Supra group and 35 patients in the Regent group. Fourteen patients did not enter the exercise protocol. One patient had an early death; 1 patient underwent valve explant because of coronary artery malperfusion; 3 patients refused further study participation; 9 patients were unable to perform treadmill exercise because of severe coxarthrosis $(n=2)$, severe obesity $(n=3)$, or atrial fibrillation $(n=3)$; and 1 patient had high blood pressure.

Exercise was discontinued on shortness of breath in $47.8 \%$, an abnormal increase in blood pressure in $21.7 \%$, dyspnea in $13.0 \%$, tachycardia in $13.0 \%$, or paradoxic decrease in blood pressure in $4.3 \%$. The average achieved workload was $86.3 \pm 19.2 \mathrm{~W}$ for the Advantage Supra group and $87.1 \pm 18.6 \mathrm{~W}$ for the Regent group. No complications occurred during treadmill exercise testing.

\section{Regurgitation}

Both valve prostheses exhibited only trivial regurgitation because of the bileaflet valve design. In addition, 1 patient in the Advantage Supra group and 1 patient in the Regent group showed moderate paravalvular regurgitation. Both patients show blood hemoglobin of 14 to $14.5 \mathrm{~g} / \mathrm{dL}$ at present, without the need for blood transfusion or ferric substitution. Lactate dehydrogenase value was slightly elevated in both patients and ranged between 250 and $400 \mathrm{U} / \mathrm{L}$. An intermittent incomplete valve closure leading to a single-beat transvalvular regurgitation, as previously described for the Advantage prosthesis, was not observed. ${ }^{17}$

\section{Patient-Prosthesis Mismatch}

Moderate PPM was observed in $8.1 \%$ of the patients in the Advantage Supra group and in $10.3 \%$ of the patients in the 
TABLE 1. Preoperative and operative data

\begin{tabular}{|c|c|c|c|}
\hline & $\begin{array}{c}\text { Advantage Supra ( } \mathrm{n}=40 \text { ) } \\
\text { (Medtronic Inc, Minneapolis, Minn) }\end{array}$ & $\begin{array}{c}\text { Regent (n= 40) (St Jude } \\
\text { Medical Inc, St Paul, Minn) }\end{array}$ & $P$ Value \\
\hline Mean age $(y)^{*}$ & $55.6 \pm 7.4$ & $55.5 \pm 10.9$ & .943 \\
\hline Gender & & & .802 \\
\hline Male & $\mathrm{n}=29$ & $\mathrm{n}=30$ & \\
\hline Female & $\mathrm{n}=11$ & $\mathrm{n}=10$ & \\
\hline \multicolumn{4}{|l|}{ Cardiac rhythm } \\
\hline Sinus rhythm & $\mathrm{n}=40$ & $\mathrm{n}=36$ & \\
\hline Atrial fibrillation & $\mathrm{n}=0$ & $\mathrm{n}=3$ & \\
\hline Paced & $\mathrm{n}=0$ & $\mathrm{n}=1$ & \\
\hline \multicolumn{4}{|l|}{ NYHA classification } \\
\hline Class I & $\mathrm{n}=1$ & $\mathrm{n}=0$ & \\
\hline Class II & $\mathrm{n}=29$ & $\mathrm{n}=30$ & \\
\hline Class III & $\mathrm{n}=7$ & $\mathrm{n}=10$ & \\
\hline Class IV & $\mathrm{n}=3$ & $\mathrm{n}=0$ & \\
\hline Mean NYHA* & $2.30 \pm 0.65$ & $2.25 \pm 0.44$ & .688 \\
\hline \multicolumn{4}{|l|}{ Aortic valve lesion } \\
\hline Isolated stenosis & $\mathrm{n}=20$ & $\mathrm{n}=26$ & \\
\hline Stenosis and regurgitation & $\mathrm{n}=20$ & $\mathrm{n}=14$ & \\
\hline Ejection fraction $(\%)^{*}$ & $60.1 \pm 12.6$ & $59.9 \pm 12.9$ & .937 \\
\hline LVM index $\left(\mathrm{g} / \mathrm{m}^{2}\right)^{*}$ & $188.0 \pm 64.7$ & $206.2 \pm 60.7$ & .208 \\
\hline Operative mortality & $\mathrm{n}=1(2.5 \%)$ & $\mathrm{n}=0(0 \%)$ & .321 \\
\hline \multicolumn{4}{|l|}{ Valve size (labeled) } \\
\hline 19 & $\mathrm{n}=0$ & $\mathrm{n}=1$ & \\
\hline 21 & $\mathrm{n}=5$ & $\mathrm{n}=9$ & \\
\hline 23 & $\mathrm{n}=15$ & $\mathrm{n}=15$ & \\
\hline 25 & $\mathrm{n}=20$ & $\mathrm{n}=15$ & \\
\hline Average labeled valve size* & $23.8 \pm 1.4$ & $23.2 \pm 1.7$ & .117 \\
\hline LVOT size $($ echo, mm)* & $24.0 \pm 1.9$ & $23.7 \pm 2.0$ & .509 \\
\hline Annulus-size (Hegar, mm)* & $23.9 \pm 1.6$ & $23.8 \pm 1.9$ & .848 \\
\hline \multicolumn{4}{|l|}{ Concomitant procedures } \\
\hline None & $\mathrm{n}=32$ & $\mathrm{n}=29$ & \\
\hline CABG & $\mathrm{n}=6$ & $\mathrm{n}=6$ & \\
\hline Other & $\mathrm{n}=2$ & $\mathrm{n}=5$ & \\
\hline Partial sternotomy & $\mathrm{n}=22$ & $\mathrm{n}=20$ & \\
\hline \multicolumn{4}{|l|}{ Aortic crossclamp (min)* } \\
\hline Isolated procedures & $69.7 \pm 16.4$ & $74.1 \pm 17.8$ & .328 \\
\hline Combined procedures & $89.8 \pm 25.6$ & $82.9 \pm 19.3$ & .525 \\
\hline Intraoperative adverse events & $\begin{array}{l}1 \text { Medtronic Advantage Supra explantation } \\
\text { because of coronary artery atresia }\end{array}$ & & \\
\hline
\end{tabular}

$C A B G$, Coronary artery bypass grafting; NYHA, New York Heart Association; $L V M$, left ventricular mass; LVOT, left ventricular outflow tract. *Results as means \pm standard deviation. $t$ test for independent samples.

Regent group; severe PPM was observed in $2.7 \%$ of the patients in the Advantage Supra group and in $2.6 \%$ of the patients in the Regent group. The incidence of PPM grouped by aortic tissue annulus diameter is shown in Table 3 .

\section{Left Ventricular Mass Regression}

The degree of LVM regression for all patients, grouped by aortic tissue annulus diameter, is shown in Table 3. LVM ndex regression at 6 months across all valve sizes was $14.8 \%$ in the Advantage Supra group $(P<.001)$ and $23.9 \%$ in the Regent group $(P<.001): 14.3 \%$ for 20 to 22
$\mathrm{mm}(P=$ not significant $), 15.1 \%$ for 23 to $24 \mathrm{~mm}(P<$ $.05)$, and $17.6 \%$ for 25 to $26 \mathrm{~mm}(P=$ not significant $)$ in the Advantage Supra group and $21.1 \%$ for 20 to $22 \mathrm{~mm}(P$ $<.05), 18.1 \%$ for 23 to $24 \mathrm{~mm}(P<.05)$, and $28.0 \%$ for 25 to $26 \mathrm{~mm}(P<.05)$ in the Regent group.

\section{Discussion}

To maximize the EOA, manufacturers have designed intrasupraannular valves with a reduced sewing ring, such as the St Jude Medical Regent valve, or complete supraannular valves, such as the Medtronic Advantage Supra valve. 
TABLE 2. Hemodynamic data at rest grouped by aortic tissue annulus diameter

\begin{tabular}{|c|c|c|c|}
\hline \multirow[b]{2}{*}{ Parameter } & \multicolumn{3}{|c|}{ Aortic tissue annulus diameter (mm) } \\
\hline & 20-22 & 23-24 & $25-26$ \\
\hline \multicolumn{4}{|l|}{ MPG (mm Hg) } \\
\hline Advantage Supra (Medtronic Inc, Minneapolis, Minn) & $18.0 \pm 4.9$ & $11.7 \pm 4.6$ & $13.8 \pm 6.5$ \\
\hline Regent (St Jude Medical Inc, St Paul, Minn) & $11.9 \pm 7.1$ & $10.6 \pm 4.2$ & $9.7 \pm 3.6$ \\
\hline \multicolumn{4}{|l|}{ SV $(\mathrm{mL})$} \\
\hline Advantage Supra & $87.5 \pm 35.4$ & $102.2 \pm 26.5$ & $112.9 \pm 30.7$ \\
\hline Regent & $74.4 \pm 16.6$ & $95.4 \pm 31.0$ & $95.2 \pm 24.7$ \\
\hline \multicolumn{4}{|l|}{$\mathrm{EOAI}\left(\mathrm{cm}^{2} / \mathrm{m}^{2}\right)$} \\
\hline Advantage Supra & $0.95 \pm 0.32$ & $1.22 \pm 0.35$ & $1.27 \pm 0.33$ \\
\hline Regent & $0.98 \pm 0.36$ & $1.04 \pm 0.32$ & $1.26 \pm 0.37$ \\
\hline \multicolumn{4}{|l|}{ EOF $(\%)$} \\
\hline Advantage Supra & $0.49 \pm 0.17$ & $0.52 \pm 0.11$ & $0.47 \pm 0.10$ \\
\hline Regent & $0.52 \pm 0.17$ & $0.48 \pm 0.13$ & $0.50 \pm 0.13$ \\
\hline
\end{tabular}

MPG, Mean pressure gradient; $S V$, stroke volume; $E O A l$, effective orifice area index; $E O F$, effective orifice fraction. Results are presented as means \pm standard deviation. ${ }^{*} P<.05$, Mann-Whitney $U$ test.

In several studies, excellent hemodynamic and clinical data are documented for the St Jude Medical Regent valve and thus serve as a benchmark in cardiovascular surgery. ${ }^{4,5}$ The Medtronic Advantage Supra valve, which is a further development of the existing Medtronic Advantage valve, is designed to be implanted in the complete supraannular position and thus is intended to provide superior hemodynamic performance with more complete LVM regression and improved clinical outcome. To date, no hemodynamic and clinical data for the Medtronic Advantage Supra valve are available in the literature.

The aim of this prospective randomized study was to evaluate the impact of complete supraannular valve positioning of mechanical bileaflet aortic valves. Therefore we analyzed the prosthesis-specific differences in valve sizing and valve size labeling, the early clinical outcome, and the hemodynamic performance during rest and exercise of a complete supraannular and an intra-supraannular bileaflet aortic valve.

\section{Comparison of Different Valve Types}

For an objective comparison of different prosthetic valve types, several issues should be considered: First, hemodynamic data and LVM regression should be based on a patient's aortic tissue annulus diameter. This is particularly important when 2 different types of valve design (eg, intrasupraannular vs complete supraannular) are compared because the labeled valve size does not represent the geometric size of the valve (Figure 1, $B$ ). Second, valve sizing for the prostheses should be undertaken before randomization using the appropriate valve sizers. As such, each surgeon was required to commit to a specific valve size before valve selection. The random assignment method used in this study prevented surgeon-specific selection bias and achieved an excellent degree of uniformity in the distribution of major preoperative and perioperative variables. Third, the EOF, which represents the ratio of the prosthetic EOA (echocardiographically obtained) and the patient's aortic annulus area (obtained by intraoperative measurement using the Hegar dilator) should be determined. It objectively reflects the EOA that can be achieved with a specific valve type in a given patient's aortic annulus. This index has been formerly described in detail by our group. ${ }^{7,18}$ The EOF is advantageous in comparisons between valves of varying manufacturers, especially since the launch of complete supraannular prostheses. Fourth, Doppler echocardiographic evaluation of the prosthetic heart valve function should be performed during exercise, because the evaluation at rest does not represent the patient's daily activities. In this context, treadmill exercise testing is the more physiologic approach compared with Dobutamine stress, despite some difficulties in obtaining reliable images in the tachypneic exercising patient. ${ }^{11,19}$ Furthermore, we added the stroke volume for each annulus size and exercise level to exclude differences in pressure gradients between both prostheses caused by different levels of blood flow. The stroke volume mainly influences the pressure gradient and therefore is the most suitable reference parameter for comparisons of hemodynamic data at stress.

\section{Operative Data and Adverse Events}

The overall operative (30 days) mortality was $1.25 \%$, with 1 early death in the Advantage Supra group. This was caused by vasopressor-induced mesenteric ischemia. An embolic event was excluded by necropsy, and therefore this death was not valve related. There were no late deaths or other prosthesis-related adverse events, such as prosthetic valve endocarditis, thromboembolism, antithromboembolic hemorrhage, or reoperation in either group. 

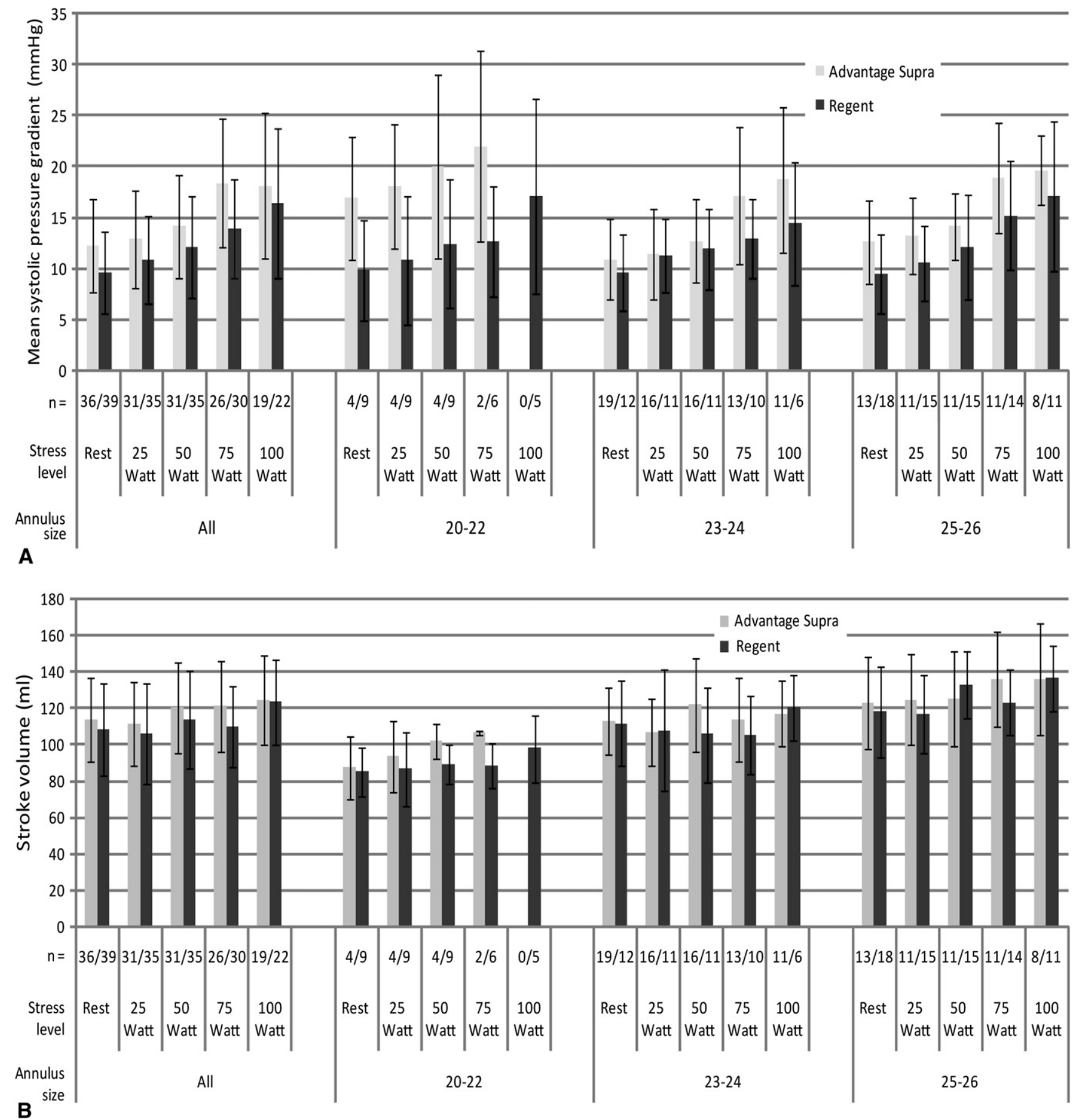

Figure 2. A, MPGs at stress grouped by aortic tissue annulus diameter. B, Stroke volume at stress grouped by aortic tissue annulus diameter.

In this series, 1 Medtronic Advantage Supra valve had to be replaced by another valve because of signs of myocardial ischemia after weaning from bypass, although the coronary arteries were without pathologic findings preoperatively. This intraoperative complication reflects the difficulty of complete supraannular valve positioning, which may impair the coronary artery perfusion caused by a higher valve position. From our experience the patient's given anatomy has to be taken into account if the implantation of a complete supraannular valve is intended, especially in the small aortic root 
TABLE 3. Incidence of patient-prosthesis mismatch and postoperative left ventricular mass regression grouped by aortic tissue annulus diameter

\begin{tabular}{|c|c|c|c|c|}
\hline \multirow[b]{2}{*}{ Annulus Size } & \multirow[b]{2}{*}{ Valve } & \multicolumn{3}{|c|}{ Patient-prosthesis mismatch } \\
\hline & & No $\left(E O A I>0.85 \mathrm{~cm} / \mathrm{m}^{2}\right)$ & Moderate $\left(E O A I \leq 0.85 \mathrm{~cm} / \mathrm{m}^{2}\right)$ & Severe $\left(\right.$ EOAI $\left.\leq 0.65 \mathrm{~cm} / \mathrm{m}^{2}\right)$ \\
\hline \multirow[t]{2}{*}{$20-22$} & $\begin{array}{l}\text { Advantage Supra (Medtronic Inc, } \\
\text { Minneapolis, Minn) }\end{array}$ & $60 \%(3 / 5)$ & $20 \%(1 / 5)$ & $20 \%(1 / 5)$ \\
\hline & $\begin{array}{l}\text { Regent (St Jude Medical Inc, } \\
\text { St Paul, Minn) }\end{array}$ & $77.8 \%(7 / 9)$ & $22.2 \%(2 / 9)$ & $0 \%(0 / 9)$ \\
\hline \multirow[t]{2}{*}{$23-24$} & Advantage Supra & $94.7 \%(18 / 19)$ & $5.3 \%(1 / 19)$ & $0 \%(0 / 19)$ \\
\hline & Regent & $75.0 \%(9 / 12)$ & $16.7 \%(2 / 12)$ & $8.3 \%(1 / 12)$ \\
\hline \multirow[t]{4}{*}{$25-26$} & Advantage Supra & $92.3 \%(12 / 13)$ & $7.7 \%(1 / 13)$ & $0 \%(0 / 13)$ \\
\hline & Regent & $100 \%(18 / 18)$ & $0 \%(0 / 18)$ & $0 \%(0 / 18)$ \\
\hline & \multicolumn{4}{|c|}{ Left ventricular mass index $\left(\mathrm{g} / \mathrm{cm}^{2}\right)$} \\
\hline & Valve & Preoperative & 6 mo postoperative & $P$ value \\
\hline \multirow[t]{2}{*}{ All } & Advantage Supra & $188.0 \pm 64.7$ & $160.3 \pm 51.7$ & $<.001$ \\
\hline & Regent & $206.2 \pm 60.7$ & $157.0 \pm 42.2$ & $<.001$ \\
\hline \multirow[t]{2}{*}{$20-22$} & Advantage Supra & $179.5 \pm 47.2$ & $153.8 \pm 47.5$ & .068 \\
\hline & Regent & $169.0 \pm 53.9$ & $133.4 \pm 35.3$ & .015 \\
\hline \multirow[t]{2}{*}{$23-24$} & Advantage Supra & $165.5 \pm 47.0$ & $140.5 \pm 39.8$ & .028 \\
\hline & Regent & $188.4 \pm 57.8$ & $154.3 \pm 39.2$ & .010 \\
\hline \multirow[t]{2}{*}{$25-26$} & Advantage Supra & $231.0 \pm 79.1$ & $190.4 \pm 57.0$ & .075 \\
\hline & Regent & $236.7 \pm 52.7$ & $170.5 \pm 43.6$ & $<.001$ \\
\hline
\end{tabular}

$E O A l$, Effective orifice area index. Results are presented as means \pm standard deviation.

where the supraannular prosthesis is in close vicinity to the coronary ostia and can therefore be responsible for intraoperative complications. ${ }^{20}$ Otherwise, the $2.5 \%$ incidence of coronary orifice obstruction may easily increase to a larger percentage of patients.

\section{Hemodynamic Data During Rest and Exercise}

In regard to the hemodynamic data at rest, there is no significant superiority of either valve in MPG, stroke volume, EOAI, and EOF when grouping the data on the basis of the patient's tissue annulus diameter. This means that complete supraannular valve positioning does not provide a better hemodynamic performance at rest, which has already been demonstrated in a prospective randomized trial with other types of complete supraannular and intra-supraannular mechanical aortic valve prostheses. ${ }^{21}$

During treadmill exercise, MPGs in the Advantage Supra group increased from $11.9 \pm 4.9 \mathrm{~mm} \mathrm{Hg}$ at rest to $19.1 \pm 7.2$ $\mathrm{mm} \mathrm{Hg}$ at $100 \mathrm{~W}$ workload and from $9.6 \pm 4.0$ to $16.4 \pm 7.3$ $\mathrm{mm} \mathrm{Hg}$ at $100 \mathrm{~W}$ workload in the Regent group. By grouping the data on the basis of a patient's tissue annulus diameter, no significant difference of either valve was detected with regard to MPG and stroke volume during exercise.

\section{Regurgitation}

The Medtronic Advantage Supra and the St Jude Medical Regent valve allow backflow on either side of both pivotal points to reduce the likelihood of thrombus formation on the prosthesis. Therefore, in all patients we observed a trivial regurgitation; in all of these cases the regurgitation was considered to be transvalvular because of the bileaflet valve design. In addition, 2 patients showed moderate paravalvular regurgitation. However, from our point of view there was no need for further intervention because of the excellent clinical condition of these patients. Within the Medtronic Advantage multicenter prospective clinical trial, an intermittent incomplete valve closure leading to a singlebeat transvalvular regurgitation was documented by our group for the Advantage valve. ${ }^{17}$ The Medtronic Advantage Supra valve is a further development of the existing Medtronic Advantage valve. Although the pivot region and the pivot guards were not changed, this intermittent incomplete valve closure was not documented in any Advantage Supra prosthesis.

\section{Patient-Prosthesis Mismatch}

PPM was identified as an important and independent risk factor for short-term mortality in patients undergoing AVR. ${ }^{22}$ Controversial debate exists with regard to PPM, focusing on the long-term results after AVR. ${ }^{23,24}$ A residual stenosis represented by low EOAI is frequently observed, especially in the small-sized aortic tissue annulus. These findings with regard to moderate to severe PPM are important because of its prevalence of $19 \%$ to $70 \%$ reported in the literature. ${ }^{25}$ 
In our study, in which the Doppler-derived EOA 6 months postoperatively was used to calculate the EOAI, the incidence of moderate and severe PPM was rare in both groups compared with the literature. Moderate PPM occurred in $8.1 \%$ in the Advantage Supra group and in $10.3 \%$ in the Regent group. The incidence of severe PPM was $2.7 \%$ in the Advantage Supra group and 2.6\% in the Regent group. There was no significant difference in the occurrence of moderate or severe PPM between both groups. In regard to EOAI, there is no significant difference between both valve types. These findings suggest that these new generations of bileaflet mechanical valves are good options to prevent PPM or reduce its severity in the aortic position.

\section{Left Ventricular Mass Regression}

In both groups, a marked and highly significant reduction in LVM across all tissue annulus sizes $(P<.001)$ was demonstrated, as well as an equal amount of mass reduction. The extent of LVM regression within 6 months was approximately $20 \%$ in both groups. This is in accordance with other studies focusing on AVR with mechanical prostheses and determination of LVM by means of transthoracic echocardiography 6 months postoperatively. ${ }^{4,14,21}$ Despite this mass regression, $75.8 \%$ of the Advantage Supra population and 76.9\% of the Regent population still presented with LV hypertrophy, when defining LV hypertrophy with LVM index greater than $131 \mathrm{~g} / \mathrm{m}^{2}$ in men and greater than $100 \mathrm{~g} / \mathrm{m}^{2}$ in women. ${ }^{26}$ In patients with aortic valve lesions, persisting LV hypertrophy is likely to be an independent risk factor for long-term survival after AVR. ${ }^{27}$ The reasons for incomplete LVM regression include residual aortic gradient caused by PPM, persistent hypertension, and nonhemodynamic factors, such as genotype. ${ }^{28}$ Furthermore, conventional 1- and 2-dimensional echocardiographic methods tend to overestimate LVM, compared with magnetic resonance imaging. ${ }^{29}$

\section{Limitations}

The population sizes were small, and the follow-up was only 6 months. Thus, the power to comment on clinical events is limited. However, the population size is not expected to affect our general conclusions about hemodynamic performance. Doppler echocardiography may overestimate the gradient and underestimate the EOA in bileaflet mechanical valves because of the phenomenon of localized high gradient. ${ }^{30}$

\section{Conclusions}

Six months after implantation, the Medtronic Advantage Supra and the St Jude Medical Regent valve provide low MPGs and high EOAs during rest and exercise and therefore provide excellent options for mechanical AVR. In particular, neither valve demonstrated a clear advantage during rest and exercise when grouping the data on the basis of a patient's tis- sue annulus diameter. PPM was rare, even in the small-sized annulus, and a significant LVM regression, an important indicator for long-term survival, was observed in all patients. With the supraannular implantation technique, the surgeon's attention has to be turned toward appropriate valve sizing. Further investigation and data collection will allow the assessment of valve performance beyond 6 months after implantation. We recommend the pressure gradients obtained during stress echocardiography to be referred to the stroke volume and the hemodynamic results obtained to be referred to the patient's annulus diameter. We conclude that there is no additional benefit of the supraannular valve positioning of the Medtronic Advantage Supra valve compared with the intra-supraannular positioning of the St Jude Medical Regent valve.

\section{References}

1. Peterseim DS, Cen Y-Y, Cheruvu S, Landolfo K, Bashore TM, Lowe JE, et al. Long-term outcome after biologic versus mechanical aortic valve replacement in 841 patients. J Thorac Cardiovasc Surg. 1999;117: 890-7.

2. Autschbach R, Walther T, Falk V, Kostelka M, Rosler A, Langebartels G, et al. Prospectively randomized comparison of different mechanical aortic valves. Circulation. 2000;102:III1-4.

3. Zellner JL, Kratz JM, Crumbley AJ 3rd, Stroud MR, Bradley SM, Sade RM, et al. Long-term experience with the St. Jude Medical valve prosthesis. Ann Thorac Surg. 1999;68:1210-8.

4. Bach DS, Sakwa MP, Goldbach M, Petracek MR, Emery RW, Mohr FW. Hemodynamics and early clinical performance of the St. Jude Medical Regent mechanical aortic valve. Ann Thorac Surg. 2002;74:2003-9.

5. Gelsomino S, Morocutti G, Da Col P, Masullo G, Carella R, Guzzi G, et al. Early in vivo hemodynamic results after aortic valve replacement with the St Jude Medical Regent mechanical heart valve in patients with pure aortic stenosis. J Card Surg. 2003;18:125-32.

6. Replacement Heart Valve Guidance. Food and Drug Administration, Version 4.1, October 1994.

7. Eichinger WB, Botzenhardt F, Günzinger R, Bleiziffer S, Keithahn A, Bauernschmitt $R$, et al. The effective orifice area/patient aortic annulus area ratio: a better way to compare different bioprostheses? A prospective randomized comparison of the Mosaic and Perimount bioprostheses in the aortic position. J Heart Valve Dis. 2004;13:382-9.

8. Eichinger WB, Botzenhardt F, Gunzinger R, Kemkes BM, Sosnowski A, Maiza D, et al. European experience with the Mosaic bioprosthesis. J Thorac Cardiovasc Surg. 2002;124:333-9.

9. Devereux RB, Alonso DR, Lutas EM, Gottlieb GJ, Campo E, Sachs I, et al. Echocardiographic assessment of left ventricular hypertrophy: comparison to necropsy findings. Am J Cardiol. 1986;57:450-8.

10. Pibarot P, Dumesnil JG, Briand M, Laforest I, Cartier P. Hemodynamic performance during maximum exercise in adult patients with the Ross operation and comparison with normal controls and patients with aortic bioprostheses. Am J Cardiol. 2000;86:982-8.

11. Eriksson MJ, Rosfors S, Radegran K, Brodin LA. Effects of exercise on Doppler-derived pressure difference, valve resistance, and effective orifice area in different aortic valve prostheses of similar size. Am J Cardiol. 1999;83:619-22, A10.

12. Pibarot P, Dumesnil JG, Lemieux M, Cartier P, Metras J, Durand LG. Impact of prosthesis-patient mismatch on hemodynamic and symptomatic status, morbidity and mortality after aortic valve replacement with a bioprosthetic heart valve. J Heart Valve Dis. 1998;7:211-8.

13. Rahimtoola SH. Perspective on valvular heart disease: an update. $J \mathrm{Am}$ Coll Cardiol. 1989;14:1-23.

14. Guenzinger R, Eichinger WB, Botzenhardt F, Bleiziffer S, Wagner I, Bauernschmitt R, et al. Rest and exercise performance of the Medtronic Advantage bileaflet valve in the aortic position. Ann Thorac Surg. 2005; 80:1319-26. 
15. O'Rourke LGC, Ghosh CP, Shu M. Unsteady 3-D computational fluid dynamic simulation of Medtronic model 7760 prosthetic mechanical heart valves. Adaptive Research Report, March 1999.

16. Yoganathan A. Laser Doppler Velocimetry Studies Within the Hinge Region of a Clear Medtronic Bileaflet Mechanical Heart Valve. Atlanta, GA: Georgia Institute of Technology; 1999.

17. Eichinger WB, Wagner I, Bleiziffer S, von Canal F, Lange R. Occasional single-beat regurgitation observed with the new Medtronic ADVANTAGE bileaflet heart valve. J Thorac Cardiovasc Surg. 2006; 131:730-1.

18. Wagner IM, Eichinger WB, Bleiziffer S, Botzenhardt F, Gebauer I, Guenzinger R, et al. Influence of completely supra-annular placement of bioprostheses on exercise hemodynamics in patients with a small aortic annulus. $J$ Thorac Cardiovasc Surg. 2007;133:1234-41.

19. Izzat MB, Birdi I, Wilde P, Bryan AJ, Angelini GD. Comparison of hemodynamic performances of St. Jude Medical and CarboMedics 21 $\mathrm{mm}$ aortic prostheses by means of dobutamine stress echocardiography. J Thorac Cardiovasc Surg. 1996;111:408-15.

20. Eichinger WB, Botzenhardt F, Wagner I, Bleiziffer S, Ruzicka D, Guenzinger R, et al. Hemodynamic evaluation of the Sorin Soprano bioprosthesis in the completely supra-annular aortic position. J Heart Valve Dis. 2005; 14:822-7.

21. Chambers J, Roxburgh J, Blauth C, O'Riordan J, Hodson F, Rimington $\mathrm{H}$. A randomized comparison of the MCRI On-X and CarboMedics Top Hat bileaflet mechanical replacement aortic valves: early postoperative hemodynamic function and clinical events. J Thorac Cardiovasc Surg. 2005;130:759-64.

22. Blais C, Dumesnil JG, Baillot R, Simard S, Doyle D, Pibarot P. Impact of valve prosthesis-patient mismatch on short-term mortality after aortic valve replacement. Circulation. 2003;108:983-8.
23. Frapier JM, Rouviere P, Razcka F, Aymard T, Albat B, Chaptal PA. Influence of patient-prosthesis mismatch on long-term results after aortic valve replacement with a stented bioprosthesis. J Heart Valve Dis. 2002; 11:543-51.

24. Rao V, Jamieson WR, Ivanov J, Armstrong S, David TE. Prosthesispatient mismatch affects survival after aortic valve replacement. $\mathrm{Circu}$ lation. 2000;102:III5-9.

25. Pibarot P, Dumesnil JG. Hemodynamic and clinical impact of prosthesis-patient mismatch in the aortic valve position and its prevention. $J$ Am Coll Cardiol. 2000;36:1131-41.

26. Tasca G, Brunelli F, Cirillo M, Amaducci A, Mhagna Z, Troise G, et al. Mass regression in aortic stenosis after valve replacement with small size pericardial bioprosthesis. Ann Thorac Surg. 2003;76:1107-13.

27. Orsinelli DA, Aurigemma GP, Battista S, Krendel S, Gaasch WH. Left ventricular hypertrophy and mortality after aortic valve replacement for aortic stenosis. A high risk subgroup identified by preoperative relative wall thickness. J Am Coll Cardiol. 1993;22:1679-83.

28. Dellgren G, Eriksson MJ, Blange I, Brodin LA, Radegran K, Sylven C. Angiotensin-converting enzyme gene polymorphism influences degree of left ventricular hypertrophy and its regression in patients undergoing operation for aortic stenosis. Am J Cardiol. 1999;84:909-13.

29. Scharhag J, Urhausen A, Schneider G, Rochette V, Kramann B, Kindermann W. [Left ventricular mass in endurance-athletes with athlete's heart and untrained subjects-comparison between different echocardiographic methods and MRI]. Z Kardiol. 2003;92:309-18.

30. Baumgartner H, Khan S, DeRobertis M, Czer L, Maurer G. Discrepancies between Doppler and catheter gradients in aortic prosthetic valves in vitro. A manifestation of localized gradients and pressure recovery. Circulation. 1990;82:1467-75. 